\title{
QUALIDADE E PRODUTIVIDADE ECONÔMICA DE CULTIVARES ALFACE CONDUZIDAS NAS CONDIÇÕES EDAFOCLIMÁTICAS DO SUDESTE PARAENSE
}

\author{
Michelane Silva Santos Lima'; Luciana da Silva Borges²; Núbia de Fátima Alves Santos ${ }^{3}$; Márcio \\ Roberto da Silva Melo ${ }^{4}$; Vitor Quintela Sousa ${ }^{5}$; Sannah Mohamad Birani6; Augusto José Silva Pedroso7; \\ Rafaelle Fazzi Gomes ${ }^{8}$.

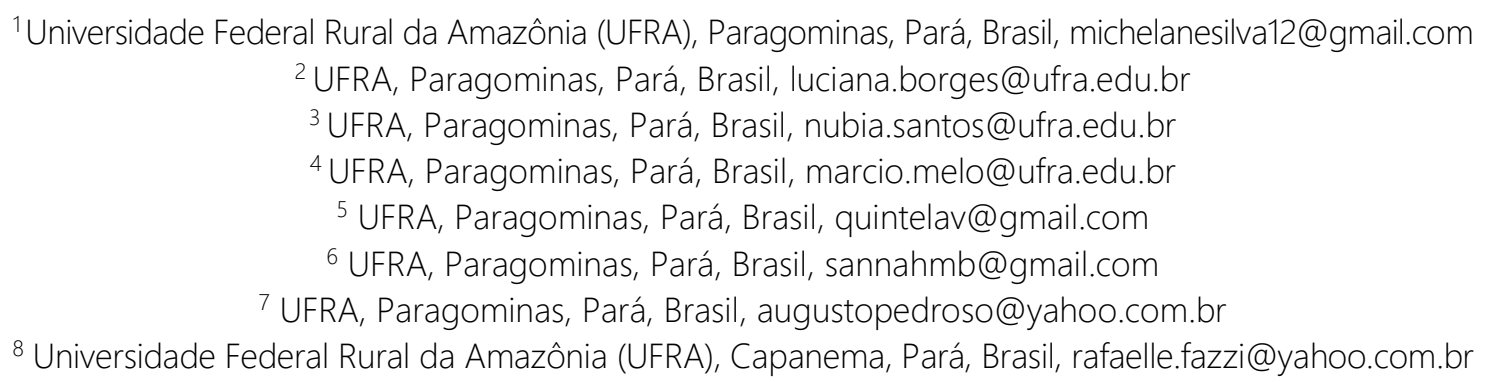

RESUMO: Dentre as hortaliças consumidas no país, a alface, encontra-se em destaque em importância econômica e com relação à produtividade. A temperatura pode influenciar significativamente na alface, modificando a sua arquitetura, produção, ciclo e capacidade de suportar ao pendoamento. Dessa forma objetivou-se determinar a produção de cultivares alface e sua qualidade sob as condições edafoclimáticas do município de Paragominas-PA. O experimento foi conduzido na Universidade Federal Rural da Amazônia, campus de Paragominas, na área experimental de Horticultura. O delineamento experimental foi em blocos casualizados, com cinco tratamentos (diferentes cultivares), e com quatro repetições, 10 parcelas, sendo avaliado cinco cultivares de alface: Rafaela, Veneranda, Maravilha quatro estações roxa manteiga, Crespa e Black. Todos os dados obtidos foram analisados estatisticamente através da análise de variância, com teste F. Quando houve significância para o fator foi aplicado teste de Tukey (1\%) para a comparação de médias. Nas condições deste experimento, pode-se verificar que a cv. Rafaela apresentou melhor produtividade econômica e melhor qualidade conforme as avaliações. No entanto as cultivares Black e Maravilha apresentaram um ciclo precoce para região. Demonstrando assim que essas três cultivares são mais adequadas para produção em regiões com alta temperatura, como é o caso da região sudeste paraense.

PALAVRAS-CHAVE: Lactuca sativa, Produção, Viabilidade. 


\title{
QUALITY AND ECONOMIC PRODUCTIVITY CULTIVARS LETTUCE LED UNDER HIGH TEMPERATURE
}

\begin{abstract}
Among the vegetables consumed in Brazil, lettuce, is highlighted in economic importance and in relation to productivity. The temperature can significantly influence the lettuce, changing its architecture, production cycle and resistance to pendoamento. The objective of this study was to determine the yield of lettuce cultivars and their quality under the soil and climatic conditions of the municipality of Paragominas-PA. The experiment was conducted at the Federal Rural University of Amazonia, campus of Paragominas, in the experimental area of Horticulture. The experimental design was a randomized block, with five treatments (different cultivars) and four replications, 10 installments, being evaluated five lettuce cultivars: Rafaela American, Veneranda, Purple Wonder four seasons butter, Crespa and Black. All data were statistically analyzed by analysis of variance with test $F$. When there was significance to the factor was applied Tukey test (1\%) for comparison of averages. Under the conditions of this experiment, cultivate rafaela showed better economic productivity and better quality as evaluators. However, the black cultivars and wonder showed an early cycle to region. Thus, demonstrating that these three cultivars are best suited for production in areas with high temperature, such as the northeast Pará region.
\end{abstract}

KEYWORDS: Lactuca sativa, Produção, Viabilidade.

\section{CALIDAD Y PRODUCTIVIDAD ECONÓMICA DE CULTIVARES LECHUGA CONDUCIDAS EN LAS CONDICIONES EDAFOCLIMÁTICAS DEL SUDESTE PARAENSE}

RESUMEN: Entre las hortalizas consumidas en el país, la lechuga, se destaca en importancia económica y con relación a la productividad. La temperatura puede influir significativamente en la lechuga, modificando su arquitectura, producción, ciclo y capacidad de soportar el pimiento. De esta forma se objetivó determinar la producción de cultivares lechuga y su calidad bajo las condiciones edafoclimáticas del municipio de Paragominas-PA. El experimento fue conducido en la Universidad Federal Rural de la Amazonia, campus de Paragominas, en el área experimental de Horticultura. En la mayoría de los casos, se observó un aumento de la producción de leche en la leche materna. Todos los datos obtenidos fueron analizados estadísticamente a través del análisis de varianza, con prueba F. Cuando hubo significancia para el factor fue aplicado test de Tukey (1\%) para la comparación de promedios. En las condiciones de este experimento, se puede verificar que la cv. Rafaela presentó mejor productividad económica y mejor calidad según los 
evaluadores. Sin embargo, las cultivares Black y Maravilla presentaron un ciclo precoz para la región. Demostrando que estos tres cultivares son más adecuados para la producción en regiones con alta temperatura, como es el caso de la región sudeste paraense.

Palabras clave: Lactuca sativa, Producción, Viabilidad.

A alface (Lactuca sativa L.) é a desempenho dessa cultura, hortaliça folhosa mais consumida no principalmente se o solo está com uma Brasil e no mundo, contribuindo na temperatura elevada, pois, pode geração de emprego e renda (ZÁRATE et al., 2010). Dentre as hortaliças consumidas no país, a alface, encontrase em destaque em importância econômica e em relação à produtividade (CEASA-ES, 2010). Estima-se que sejam cultivados em torno de 35 mil hectares anualmente no Brasil (LOPES et al., 2010). O consumo ocorre principalmente na forma in natura. Essa espécie apresenta grande importância na alimentação humana, em especial por ser fonte de vitaminas e sais minerais (SILVA et al.,2011).

A temperatura pode interferir significativamente na alface, modificando sua arquitetura, produção, ciclo e firmeza ao pendoamento (DIAMANTE et al., 2013), a temperatura elevada é um dos fatores limitantes ao ocasionar estresse à planta, aumentando 0 metabolismo, impedindo a absorção de nutrientes e prejudicando o crescimento da raiz (SANTOS et al., 2010). No cultivo de oleráceas no Brasil, o cultivo em casa de vegetação é largamente utilizado com o intuito de diminuir o impacto adverso do clima, como, por exemplo, granizos, geadas, vento, o que soma a possibilidade de proporcionar aumento na produtividade e na qualidade de produtos (OLIVEIRA et al., 2011).

A dificuldade de adaptação de algumas cultivares de alface a temperaturas altas tem impedido que a cultura expresse todo o seu potencial genético, antecipando sua fase reprodutiva, o que reduz seu ciclo e compromete sua produção. Além disso, 
temperaturas elevadas modificam a textura das folhas de alface, tornandoas mais fibrosas (SETÚBAL; SILVA, 1992).

Diante disto, o objetivo deste trabalho foi avaliar a produção de alface sob as condições edafoclimáticas no município de Paragominas no estado do Pará.

O experimento foi conduzido na Universidade Federal Rural da Amazônia, campus de Paragominas, na área experimental de Horticultura. $\bigcirc$ município de Paragominas está entre as coordenadas geográficas $02^{\circ}$ 55'24" S e $47^{\circ} 34^{\prime} 36^{\prime \prime} W$. Os solos da área de estudo são do tipo Latossolo Amarelo muito argiloso (EMBRAPA, 2008). O clima da região é do tipo Awi, segundo a classificação de Köppen, isto é, tropical chuvoso com estação seca bem definida, com temperatura média anual de $26,5^{\circ} \mathrm{C}$. Este ensaio foi realizado a campo aberto no período de altas temperaturas, foi avaliado cinco cultivares de alface: Rafaela-Americana, Veneranda, Maravilha quatro estações roxa manteiga, Crespa e Black. O delineamento experimental utilizado foi blocos ao acaso, com cinco tratamentos (diferentes de cultivares), e com quatro repetições, 10 parcelas. Estas contendo 12 plantas, das quais seis foram utilizadas para avaliação dos parâmetros de produção e qualidade, as demais foram consideradas bordaduras.

A umidade relativa do ar varia de 70\% a 90\% (RODRIGUES et al., 2002). No preparo do canteiro definitivo foi utilizada enxada rotativa (microtrator) e roto-encanteirador para uniformização (altura de $20 \mathrm{~cm}$ ), evitando também o encharcamento do solo pela irrigação constante. Permanecendo com 0,2 m de altura por $11 \mathrm{~m}$ de comprimento e 1 m de largura.

$\mathrm{Na}$ área experimental foi coletada amostra para a realização de análise química do solo antes da implantação do experimento (Tabela 1). Com base nos resultados não foi necessário a correção, pois já apresentava saturação por base a $70 \%$ conforme exigência da cultura. 
Tabela 1. Análise do solo antes do início do experimento. Paragominas, Pará, 2016.

\begin{tabular}{|c|c|c|c|c|c|c|c|c|c|c|}
\hline Amostra & $\begin{array}{l}\text { M.O } \\
\text { g/dm }\end{array}$ & $\begin{array}{c}\mathrm{pH} \\
\mathrm{CaCl} 2\end{array}$ & $\begin{array}{c}P \\
\text { Resina } \\
\mathrm{mg} / \mathrm{dm}^{3}\end{array}$ & $\begin{array}{c}\text { K } \\
\text { Trocável }\end{array}$ & $\begin{array}{c}\text { Ca } \\
\text { Trocável }\end{array}$ & $\begin{array}{c}\text { Mg } \\
\text { Trocável } \\
\text { mmolc/dr }\end{array}$ & $\begin{array}{c}\mathrm{H}+\mathrm{Al}^{3} \\
\text { mmolc/dr }\end{array}$ & S.B. & $\begin{array}{l}\text { C.T.C } \\
\text { g/dm }{ }^{3}\end{array}$ & V\% \\
\hline Solo & 39 & 5.3 & 28 & 2.4 & 40 & 10 & 34 & 52,4 & 86,4 & 61 \\
\hline Amostra & $\begin{array}{c}\mathrm{S} \\
\mathrm{mg} / \mathrm{dm}^{3}\end{array}$ & $\mathrm{Ca} / \mathrm{Mg}$ & $\mathrm{Ca} / \mathrm{K}$ & $\mathrm{Mg} / \mathrm{k}$ & $\mathrm{K}$ na C & $\begin{array}{l}\text { TC Fosfato } \\
\text { de } \%\end{array}$ & $\begin{array}{l}\text { Ca na } \\
\text { Cálcio }\end{array}$ & & $M g r$ & CTC \\
\hline
\end{tabular}

\begin{tabular}{cccccccc}
\hline Solo & 8 & 4 & 16,7 & 4,2 & 2,8 & 46,3 & 11,6
\end{tabular}

Onde: (a) Cálcio; Mg) Magnésio; Al) Alumínio; H+Al) Acidez Potencial; SB) Soma de Bases; (TC) Capacidade de Troca de Cátions (CTC); V) Saturação em Bases; M.O.) Matéria Orgânica; P resina) Fósforo; S) Enxofre.

Fonte: Elaboração dos autores.

\section{A semeadura foi realizada em} bandejas de poliestireno expandido de 128 células, preenchidas com substrato comercial Turfa fértil, com as seguintes características: $\mathrm{pH}$ 5,8 + ou - 0,5, condutividade elétrica $(\mathrm{mS} / \mathrm{cm}): 0,7+$ ou - 0,3, umidade máxima (\% peso/peso): 55, densidade em base seca $\left(\mathrm{kg} / \mathrm{m}^{3}\right)$ : 260, capacidade de retenção de água + CRA (\%):60. Matéria prima: turfa e casca de arroz carbonizado, aditivado com N (0,04\%), P205 (0,04\%), K20 (0,05\%) e calcário calcitíco (1,5\%). Em cada célula foram colocadas de três sementes de alface e foi realizado o desbaste das mudas aos dois dias após a emergência, permanecendo uma muda por célula.
As bandejas foram dispostas sobre bancadas com 0,7 $\mathrm{m}$ de altura em viveiro, sob ambiente protegido coberto com filme plástico de polietileno.

A adubação de plantio foi definida com base nas recomendações de Trani e Raij (1997), e a análise de solo realizada (Tabela 1), aplicando-se 10 $\mathrm{Kg} / \mathrm{m}^{2}$ de cama de aviário, $100 \mathrm{~g} / \mathrm{m}^{-2}$ de ureia, $50 \mathrm{~g} / \mathrm{m}^{-2}$ de Cloreto de Potássio (56\% de $\left.\mathrm{K}_{2} \mathrm{O}\right)$, e $150 \mathrm{~g} / \mathrm{m}^{-2}$ de superfosfato simples, junto com areia preta.

O transplante foi realizado quando as mudas estavam com quatro folhas definitivas, aos 34 dias após a semeadura. Foi realizada a caracterização das mudas, utilizando-se 
20 plantas, coletadas aleatoriamente nas bandejas no dia do transplante.

As mudas foram dispostas em canteiro com três fileiras, utilizando o espaçamento de $30 \mathrm{~cm}$ entre plantas e $30 \mathrm{~cm}$ entre fileiras, totalizando 12 plantas por parcela.

Para o fornecimento de água no experimento, foi adotado um sistema de irrigação por aspersão, por meio de fitas tipo santeno I, disposta entre os canteiros, que foram instaladas na superfície do solo. A fita apresentava as seguintes características: com pressão de serviço: 0,2 a 0,8 kgf/ $\mathrm{cm}^{2}$, distância entre emissores: $0,15 \mathrm{~m}$ a 1,05m, diâmetro dos emissores: 0,3 mm, diâmetro da mangueira: 28mm, espessura da parede: 0,20 mm/200m, raio de alcance: $2,5 \mathrm{~m}$, altura dos jatos 1,80 m e a posição dos emissores: centrais, sendo realizadas duas vezes ao dia.

A adubação de cobertura foi definida com base nas recomendações de Trani e Raij (1997) e a análise de solo realizada (Tabela 1) com $50 \mathrm{~g} \mathrm{~m}^{-2}$ de NPK na formulação de (15-15-20), sendo 15 partes de nitrogênio, 15 partes de fósforo e 20 partes de potássio, aos 30, 45 e 60 dias após o transplante e a adubação via foliar com ácido bórico 1 $\mathrm{g} \mathrm{L}^{-1}$ ocorrendo aos 30 e 45 dias após o transplante.

As capinas foram realizadas a cada sete dias, desde o início da instalação da cultura. No período inicial, a capina foi realizada com auxílio de enxadas. Quando as plantas já se apresentavam mais desenvolvidas, a capina passou a ser manual, para não danificar as plantas. Não houve ocorrência de doenças no período do experimento em nenhuma cultivar de alface produzida. Com relação a pragas,

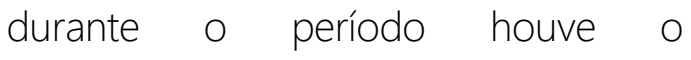
aparecimento de formigas nos canteiros, e para o controle foi utilizada uma solução de NIM, onde foi preparada uma emulsão com 500 g de folhas de NIM (com os talos) e 20 litros de água, essa mistura ficou descansando por vinte quatro horas. Foi utilizada cerca de 100 mililitros da solução ao redor de cada planta, aplicadas semanalmente. 
$\mathrm{Na}$ colheita foram colhidas e avaliadas seis plantas centrais de cada parcela aos 56, 67 e 76 dias após a semeadura, quando atingiram o máximo desenvolvimento vegetativo, antes de iniciarem o processo de pendoamento. A colheita das plantas foi realizada nas primeiras horas da manhã, foram selecionadas e transportadas, imediatamente, ao Laboratório de Horticultura, as partes foram lavadas em água corrente e detergente neutro, para retirada do calor de campo e grandes impurezas. Em seguida, foram colocadas sob papel absorvente para a retirada de excesso de água. As características avaliadas foram:

O número de folhas por planta foi obtido pela contagem do número de folhas por muda (6 plantas).

Diâmetro transversal/longitudinal: foi obtido a partir de trinta folhas selecionadas aleatoriamente de seis mudas em análise, com uso de paquímetro.

Peso (g): foi obtido a pesagem por muda de seis plantas em análise em balança de precisão.
Peso bordadura (g): foi feita a pesagem da massa fresca de seis plantas consideradas bordaduras em balança de precisão.

Distúrbios fisiológicos: foi quantificado a partir da ocorrência dos distúrbios para alface. Esta avaliação foi feita no momento da colheita avaliando-se seis plantas por parcela;

Ciclo: foi determinado com a contagem dos dias entre a semeadura e a colheita;

Produtividade econômica: Foi calculada através da massa fresca pelo número de plantas por metro quadrado.

Análise sensorial: Para avaliação dos atributos sensoriais, foram convidados vinte provadores não treinados, consumidores de alface. Foram avaliados os seguintes atributos: aparência externa, odor, desidratação, escurecimento, sabor, textura e qualidade global. Os consumidores degustavam e preenchiam uma ficha contendo uma escala com nota para cada um dos atributos, a ficha continha as seguintes informações: 
Escala geral: 1- muito ruim, 2- ruim, 3- aceitável como limite de consumo, 4bom, 5- muito bom.

Escala de textura: 1- muito branda, 2branda, 3- aceitável como limite de consumo, 4- firme, 5- muito firme.

Escala desidratação: odores: 5muita/o, 4- bastante, 3- aceitável como limite de consumo, 2- leve, 1nenhuma/o.

Escala de escurecimento: 5- mais de 70\%, 4- entre 70 e 50\%, 3- entre 50 e 30\%, 2- entre 30 e 10\%, 1 menos de 10\%.

Todos os dados obtidos foram analisados estatisticamente através da análise de variância, com teste F. Quando houve significância para o fator foi aplicado teste de Tukey (5\%) para a comparação de médias. Todas as análises realizadas foram feitas pelo do programa SISVAR (FERREIRA, 2000).

Verificou-se pelos resultados apresentados na Tabela 2, que o diâmetro longitudinal nas cultivares Maravilha, Crespa, Black, Veneranda e Rafaela, não apresentou diferença estatística no seu desempenho, com tamanho entre $17,22 \mathrm{~cm}$ e 20,58 cm (Tabela 2). Sediyama et al. (2000), afirmaram que o tamanho exagerado de folhas muitas vezes é indesejável pela dificuldade de embalagem pelos danos causados às folhas.

Tabela 2. Produtividade das cultivares alface cultivadas nas condições edafoclimáticas do nordeste paraense, Paragominas, Pará, UFRA, 2014.

\begin{tabular}{|c|c|c|c|c|c|c|c|c|}
\hline Cultivares & $\begin{array}{l}\text { D.L } \\
(\mathrm{cm})\end{array}$ & & $\begin{array}{l}\text { D. T } \\
(\mathrm{cm})\end{array}$ & & $\begin{array}{l}\text { PESO } \\
(\mathrm{g})\end{array}$ & No Folha & $\begin{array}{l}\text { P. B. } \\
\text { (g) }\end{array}$ & $\begin{array}{l}\text { Prod. } \\
\left(\mathrm{kg} / \mathrm{m}^{2}\right)\end{array}$ \\
\hline Maravilha & $17,22 \mathrm{~b}$ & $a$ & 10,64 & $c$ & 0,42 a & $24,33 c$ & $0,47 \mathrm{~b} a$ & $2,53 \quad a$ \\
\hline Crespa & 15,58 & a & $11,69 \mathrm{c}$ & $b$ & $0,36 \mathrm{~b} a$ & $25,83 \mathrm{c}$ & $0,35 \mathrm{c}$ & $2,21 \mathrm{~b} \mathrm{a}$ \\
\hline Black & 17,04 b & a & $14,32 \mathrm{c}$ & $b$ & 0,45 a & $15,70 d$ & 0,54 a & $2,72 \quad a$ \\
\hline Veneranda & $18,10 \mathrm{~b}$ & a & 15,22 & $b$ & $0,30 \mathrm{~b}$ & 29,87 b & $0,23 d$ & $1,81 \quad b$ \\
\hline Rafaela & 20,58 & a & 20,08 & a & 0,45 a & 36,31 a & $0,43 \mathrm{~b}$ & $2,74 \quad a$ \\
\hline CV (\%) & 12,19 & & 13, & & 12,93 & 6,24 & 8,74 & 12,86 \\
\hline
\end{tabular}

Letras minúsculas comparam médias das cultivares. Médias seguidas das mesmas letras não diferem estatisticamente entre si pelo teste de Tukey à $1 \%$ de probabilidade. D.L.: Diâmetro longitudinal, D.T. Diâmetro Transversal; P.B.: Peso Bordadura; Prod.: Produtividade

Fonte: Elaboração dos autores. 
Quanto aos resultados de diâmetro transversal a cultivar Rafaela obteve maior desempenho, sendo superior as demais, apresentando em média 20,08 cm em relação a cultivar Maravilha que apresentou resultado inferior de 10,64 cm (Tabela 2). Destacamos que as alfaces foram produzidas em canteiros com exposição total ao sol. Diante destes fatos SANTOS et al. (2010), afirmam que uma alternativa para o cultivo de alface é o uso de ambientes protegidos como o emprego de telados (telas termo-refletoras e de sombreamento).

Quanto ao peso não se constatou diferença significativa entre as cultivares Maravilha, Black e Rafaela, com o peso variando 0,369 a 0,457 g. Dentre as cultivares que obtiveram menor peso, a cultivar Veneranda apresentou peso inferior, em média 0,302 g (Tabela 2). Quanto ao peso bordadura, dentre as cultivares, a cultivar Black apresentou o melhor resultado com 0,548g, em relação a cultivar Veneranda que obteve menor destaque com 0,236g. Ressaltando que as plantas foram produzidas com exposição total ao sol, que pode ter sido um dos fatores que afetou no desenvolvimento do peso (Tabela 2). Para Castoldi et al. (2006), o uso da prática de cobertura de canteiros pode permitir que o produtor colha alfaces de melhor qualidade e ainda com maior volume e peso.

Com relação ao número de folha, a cultivar Rafaela obteve melhor desempenho, apresentando uma média 36,316 folhas (Tabela 2). Este resultado discorda com os resultados encontrados por Andrade Júnior e Klar (2010), que apresentou queda no número de folhas. Durante o período que o experimento foi conduzido, a temperatura encontrava-se elevada, com média $35 \mathrm{C}^{\circ}$, o que pode ter influenciado no seu desenvolvimento. Segundo SILVA et al. (2000), a baixa adequação da alface à temperatura tem dificultado a cultura de expressar todo o potencial genético, prejudicando o crescimento das folhas, e consequentemente a produção. 
Com relação a produtividade cultivar Rafaela apresentou 2,74 kg/m², resultado superior a cultivar veneranda com 1,81 kg/m². Segundo Zeng et al. (2009), o manejo criterioso da irrigação, contribui com o aumento na produtividade de diversas hortaliças bem como na melhoria da qualidade do produto. Destacamos que nesse experimento foi utilizado o sistema de irrigação por aspersão, mantendo-se um controle e uma intensidade, o que provavelmente deve ter contribuindo para esse resultado.

O ciclo das cultivares Black e Maravilha foi de 57 dias, entre semeadura e colheita, nas condições edafoclimáticas do sudeste paraense, sendo que a cultivar Black tem um ciclo de 60 a 65 dias, e a cultivar Maravilha um ciclo de 70 dias, segundo as informações descritas pelo fornecedor das sementes. Demostrando assim, que essas cultivares tem um ciclo precoce para a região, tornam-se viáveis para produção no sudeste paraense. Os materiais que apresentaram o maior ciclo foram as cultivares Crespa e Veneranda ambas com 67 dias, e a cultivar Rafaela com 76 dias. Segundo as informações descritas pelo fornecedor das sementes, o ciclo da cultivar Crespa é de 55 a 65 dias, Veneranda de 60 dias e da cultivar Rafaela 60 a 65. Para Frantz et al. (2004), a produção de alface do grupo americana é esperada desempenho morfológico diferente, se colocadas a situações de clima e solo distinto. Isso se deve aos fatos que ocorrem na fase de formação da planta podendo envolver respostas do metabolismo das plantas relacionadas ao clima e outros fatores que podem atuar individualmente ou em conjunto, conforme Araújo et al. (2010), relatam ao analisar, o comportamento da CV. Rafaela americana, cultivada em diferentes ambientes.

Com relação aos distúrbios fisiológicos, verificou-se durante a condução do experimento que houve o estiolamento da cultivar Black. Provavelmente esse distúrbio ocorreu em função da temperatura que oscilou entre $35^{\circ}$ e $39^{\circ}$ Essas temperaturas são 
desfavoráveis ao cultivo da alface, pois a variação ótima para a cultura é de 4 a $27^{\circ} \mathrm{C}$, afirmam Puiatti e Finger, (2005). Em regiões quentes, ou em época de verão, se a alface é exposta a temperaturas altas durante $\mathrm{O}$ crescimento vegetativo, ela passa rapidamente para a fase reprodutiva, ocorrendo o estiolamento (alongamento do caule) e, posteriormente, o surgimento da inflorescência, o que desvaloriza a produção comercial ao promover colheitas antecipadas e de qualidade inferior (TIBIRIÇÁ et al., 2004).

Com relação a análise sensorial (Figura 2), verifica-se que as cultivares
Black, Maravilha, Crespa, Veneranda e Rafaela, não apresentaram mudança externa conforme a avaliação dos consumidores.

Quanto os atributos analisados odor e desidratação, não foi percebida alteração em relação as cultivares Rafaela, Veneranda e Maravilha, sendo que a cultivar Black segundo os provadores apresentou odor e desidratação com característica leve. Pode-se observar que para o atributo escurecimento, as cultivares Black, Crespa, Veneranda e Rafaela não apresentaram diferença entre si, com resultado menor que $10 \%$ segundo os provadores (Figura 2).

Figura 2. Análise sensorial em cultivares de alface, cultivadas nas condições edafoclimáticas do nordeste paraense, UFRA, Paragominas, Pará.

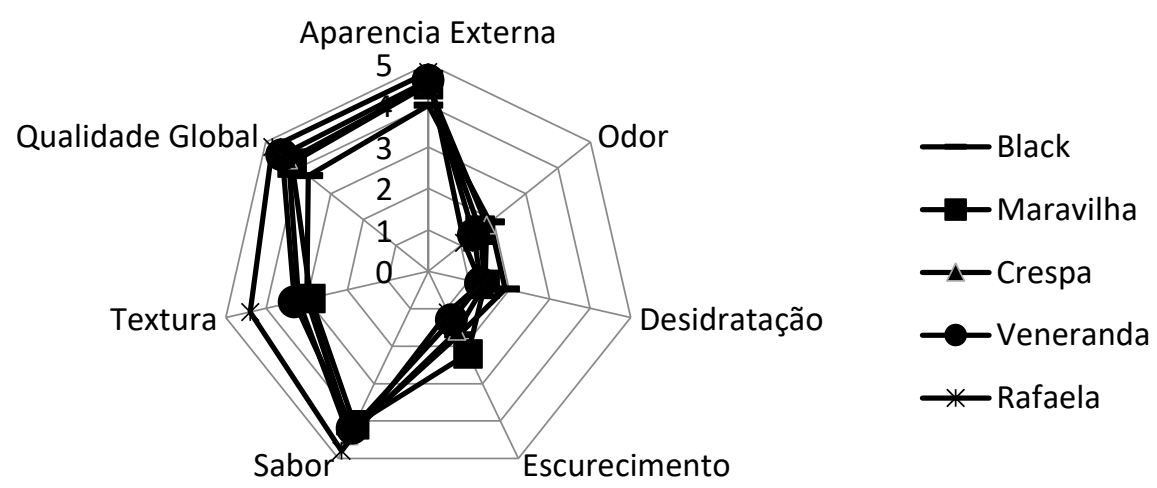

Fonte: Elaboração dos autores. 
Para os consumidores a cultivar Maravilha apresentou escurecimento entre $30 \%$ e 10\%, no entanto essa cultivar é caracterizada com alface roxa. Segundo Sala e Costa (2005), tradicionalmente o consumidor prefere alface de coloração verde pois, muitos ainda não são adeptos da alface de coloração roxa, apesar de a mesma conter três vezes mais antocianina que as alfaces comuns e um teor maior de antioxidantes, que ajudam no combate ao envelhecimento.

Quanto ao atributo sabor não houve diferença significativa entre as cultivares, apresentando resultado bom, segundo os consumidores. Para textura a cultivar Rafaela recebeu as melhores notas, pelos provadores as cultivares Black, Crespa e Veneranda obtiveram textura aceitável como limite de consumo, em relação a cultivar Maravilha foi percebida textura branda.

Quanto à qualidade global a cultivar Black apresentou menor resultado em relação as demais cultivares que não apresentaram diferença significativa.
Nas condições deste experimento, pode-se verificar que a cultivar rafaela apresentou melhor produtividade econômica e melhor qualidade conforme os avaliadores. No entanto as cultivares black e maravilha apresentaram um ciclo precoce para região. Demonstrando assim que essas três cultivares são mais adequadas para produção em regiões com alta temperatura, como é o caso da região sudeste paraense.

\section{REFERÊNCIAS}

ANDRADE JUNIOR, A. S. de; KLAR, A. E. Manejo da irrigação da cultura de alface (Lactuca sativa L.) através do tanque classe A. Scientia Agricola, Piracicaba, vol.54, n.1-2, Jan./Aug.1997. Disponível em: < http://www.scielo.br/scielo.php?script= sci_arttext\&pid=S0103-

90161997000100005> Acesso em: 29 mar. 2010.

ARAÚJO, S.T.; FIDELES FILHO, J.; KUMAR, K.K.; RAO, T.V.R. Crescimento da alface americana em função dos ambientes, épocas e graus dias. Revista Brasileira de Ciências Agrárias, v. 5, p. 441-449, 2010.

CASTOLDI, R.; CHARLO, H.C.O.; ITO, L.A.; BRAZ, L.T. Effect of plastic film mulch on the production of butterhead 
lettuce cultivars under protected cultivation. In: XXVII International Horticultural Congress, Acta Horticulturae, Leuven, v. 767: p. 205. 2006.

CEASA - ES: Centrais de Abastecimento do Espírito Santo. Disponível em: Acesso em: 01 de mar. de 2010.

DIAMANTE, M.S.; SEABRA J., S.; INAGAK, A.M.; SILVA, M.B.; DALLACORT, R. Produção e resistência ao pendoamento de alfaces tipo lisa cultivadas sob diferentes ambientes. Revista de Ciências Agronômicas, n.1, p.133-140, 2013

EMBRAPA, Centro Nacional de Pesquisa de Solos, Rio de Janeiro, Sistema Brasileiro de Classificação de Solos, Brasília-DF, Embrapa Solos, 2008, 412p.

FERREIRA, N.S.C. Gestão Democrática da Educação para uma formação humana: conceitos e possibilidades. In: Em Aberto. Brasília, v. 17, n 072. Fev/jun.2000b.

FRANTZ, J.M.; RITCHIE, G.; COMETTI, N.N.; ROBINSON, J.; BUGBEE, B. Exploring the limits of crop productivity: beyond the limits of tip-burn in lettuce. Journal of the American Society for Horticultural Science, v. 129, p. 331-338, 2004.

LOPES, C.A.; SILVA, J.B.C; GUEDES, I.M.R. Doenças da alface. Brasília: Embrapa Hortaliças, 2010. 68 p.
OLIVEIRA, E.C.; CARVALHO, J.S.; REZENDE, F.C.; FREITAS, W.A. Viabilidade técnica e econômica da produção de ervilha (Pisum sativum L.) cultivada sob diferentes lâminas de irrigação. Engenharia Agrícola, v. 31, p. 324-333, 2011.

PUIATTI, M; FINGER, F.L. Fatores climáticos. In: PAULO CRF (ed). Olericultura-teoria e prática. 1ed. Rio Branco: Suprema Gráfica e Editora. v.1. p. 17-38. 2005.

SALA, F.C.; COSTA, C.P. "PIRAROXA": cultivar de alface crespa de cor vermelha intensa. Horticultura Brasileira 23: 158- 159. 2005.

SANTOS, L.L.; SEABRA JUNIOR, S.; NUNES, M.C.M. Luminosidade, temperatura do ar e do solo em ambientes de cultivo protegido. Alta Floresta, Revista de Ciências AgroAmbientais, v. 8, n. 1, p. 83-93, 2010

SEDIYAMA, M.A.N.; PEDROSA, M.W.; GARCIA, N.C.P.; GARCIA, S.R.L. Seleção de cultivares de alface para cultivo hidropônico. In: Congresso Brasileiro de Olericultura, 40., 2000, São Pedro. Resumos...São Pedro: Sociedade Brasileira de Olericultura, 2000. p.244245.

SETÚBAL, J.W; SILVA, A.M.R. Avaliação do comportamento de alface de verão em condi- ções de calor no município de Teresina-PI. Horticultura Brasileira 10: 69, (Resumo 127), 1992.

SILVA, V.F.; BEZERRA NETO, F.; NEGREIROS, M.Z.; PEDROSA, J.F. 
Comportamento de cultivares de alface em diferentes espaçamentos sob temperatura e luminosidade elevadas. Horticultura Brasileira, v. 18, p. 183-187, novembro 2000.

SILVA, E. M. N. C. P.; FERREIRA, R.L.F.; ARAÚJO NETO, S. E.; TAVELLA, L.B.; SOLINO A.J.S. Qualidade de alface crespa cultivada em sistema orgânico, convencional e hidropônico. Horticultura Brasileira, v. 29, n. 02, p. 242- 245, 2011.

TIBIRIÇÁ, G.C.A.; BRITO, A. A.; BAÊTA, F.C. Produção de alface no verão: estufas como ambiente de cultivo, ENEGEP, 2004 ABEPRO, p.421.

TRANI, P. E.; RAIJ, B. van. Hortaliças. In: RAIJ, B. van; CANTARELLA, H.; QUAGGIO, J. A.; FURLANI, Â. M.C. Recomendações de adubação e calagem para o estado de São Paulo. 2 ed. Campinas: IAC, 1997. p. 157-185. (Boletim técnico 100).

ZÁRATE, A.H.N.; VIEIRA, M.C.; HELMICH, M.; HEID, M.D.; MENEGATI, T.C. Produção agroeconômica de três variedades de alface: cultivo com e sem amontoa. Revista Ciência Agronômica, v. 41, n. 4, p. 646-653, 2010.

ZENG, C.; BIE, Z.; YUAN, B. Determination of optimum irrigation water amount for drip-irrigated muskmelon (Cucumis melo L.) in plastic greenhouse. Agricultural Water Management, v. 96, p.595-602, 2009. 